\title{
SENSITIVITY AND VALIDITY OF A FUNCTIONAL TEST FOR AGILITY PERFORMANCE IN WATER POLO PLAYERS
}

\author{
Guilherme Tucher ${ }^{1}$, Flávio A. de S. Castro², António J.R.M. da Silva ${ }^{3}$, and Nuno D. Garrido ${ }^{3}$ \\ ${ }^{I}$ Center of Physical Education and Health, Federal Institute of Education, \\ Science and Technology of the Southeast of Minas Gerais, Rio Pomba, Minas Gerais, Brazil \\ ${ }^{2}$ School of Physical Education, Federal University of Rio Grande do Sul, \\ Porto Alegre, Rio Grande do Sul, Brazil \\ ${ }^{3}$ Sports Science Department, University of Trás-os-Montes and Alto Douro, Vila Real, Portugal
}

Original scientific paper

UDC: 797.253:796.012.21

\begin{abstract}
:
The aim of this study was to evaluate the sensitivity and validity of the Functional Test for Agility Performance (FTAP) in water polo players. Six elite junior (aged 16.33 \pm 0.82 years) male players and 65 competitive men (aged 18.1 \pm 4.3 years) who were classified in three groups $\left(\mathrm{G}_{1-3}\right)$, participated in different phases of the test. The scores accomplished in FTAP at two periods (initial and final) were compared. They were correlated with the scores in Sprint/Agility Test and differences between standards of competition $\left(\mathrm{G}_{1-3}\right)$ were assessed. Performance differences were assessed using the paired $t$-test and Pearson's correlation was used to determine the association with agility time in the Speed/Agility Test. Differences between standards of competition were assessed using ANOVA. The final Functional Test for Agility Performance was performed in fewer seconds compared to initial $(\mathrm{p}=.002, \mathrm{r}=.94)$. No significant correlation was found between Functional Test for Agility Performance and Speed/Agility Test $(\mathrm{r}=.42, \mathrm{p}=.40)$, as expected and evidencing the discriminant validity. Differences were found between $G_{1}$ and $G_{3}(p<.001)$ and $G_{2}$ and $G_{3}$ $(\mathrm{p}=.008)$. The Functional Test for Agility Performance showed adequate sensitivity and validity, and thus is a decision-making test that can be used to assess training and expertise.
\end{abstract}

Key words: assessment, evaluation, measurement, validity, statistics

\section{Introduction}

Various tests have been used to assess performance of water polo players. Some of them are conducted on dry land (Aleksandrovi, Naumovski, Radovanovi, Georgiev, \& Popovski, 2007; Kos, Rynkiewicz, Zurek, Zabski, \& Rynkiewicz, 2010) and others in water. In general, they were developed to assess sport-specific characteristics under simulated conditions of actual situations encountered in water polo games (Uljevic, Spasic, \& Sekulic, 2013). However, such tests generally assess technical, physical, and physiological capabilities in closeaction situations. Anaerobic (Bampouras \& Marrin, 2009) and aerobic fitness (Mujika, McFadden, Hubbard, Royal, \& Hahn, 2006; Rechichi, Dawson, \& Lawrence, 2000), vertical jump (Platanou, 2006; Uljevic, et al., 2013), swimming sprint (Uljevic, Esco, \& Sekulic, 2014; Uljevic, et al., 2013), ballthrowing (Alcaraz, et al., 2011; Ferragut, et al., 2011; Uljevic, et al., 2013), passing precision (Uljevic, et al., 2013, 2014) and the eggbeater kick (Uljevic, et al., 2013, 2014) tests are examples of these close- action situations. Despite the importance of cognitive function, anticipation, and decision making in team sports (Sheppard \& Young, 2006; Sheppard, Young, Doyle, Sheppard, \& Newton, 2006; Young \& Willey, 2010), only the studies conducted by Falk, Lidor, Lander, and Lang (2004) and Tucher, Castro, Garrido, and Silva (2014) have involved the types of open-actions utilized in water polo.

Falk et al. (2004) assessed quality of decisions making in water polo players during games using subjective coaching analyses as the reference (i.e. anticipating on-going activities and making appropriate decisions), and found that better standard athletes achieved higher scores. Thus, Falk et al. (2004) proposed that additional components of cognitive functions used in water polo should be identified and tested in future studies (Falk, et al., 2004). Moreover, they suggested that an effective test should simultaneously assess cognitive, physical, and technical requirements of the game. The Functional Test for Agility Performance (FTAP) is considered to be an open skill test (Tucher, et 
al., 2014). During FTAP, the tested athlete must move as quickly as possible (physical and technical skills) in a square area in response to a pass made by another players (cognitive ability: decision making). Therefore, to respond faster, the tested athlete should pay attention to both the ball and movements of the other players (opponents). We believe that skilled water polo players move significantly faster and spend less time making decisions compared to novice players (Veale, Pearce, $\&$ Carlson, 2010; Young \& Willey, 2010).

Although one previous study (Tucher, et al., 2014) has already tested reliability of the FTAP application to assessing young players, additional evidence of the test's sensitivity and validity are required before it can be widely used by water polo teams and players. An evaluation of sensitivity involves the ability of a test to detect small changes in performance following a period of intervention training (Bangsbo, Iaia, \& Krustrup, 2008; Currell $\&$ Jeukendrup, 2008). For example, Mujika et al. (2006) evaluated 18 water polo players who took the Water Polo Intermittent Shuttle Test (WIST) five times throughout a season to track changes in their physical fitness levels. An assessment of validity measures how well a test actually measures what it is designed to measure (Currell \& Jeukendrup, 2008; Impellizzeri \& Marcora, 2009) and the selected method depends on its purpose and its applications (Impellizzeri \& Marcora, 2009).

In general, validity studies have examined the differences between groups of players with different characteristics (Bangsbo, et al., 2008; Impellizzeri \& Marcora, 2009) or correlated the performance on a test with a criterion of measurement (Bangsbo, et al., 2008; Zhu, 2000). But in this specific case, Zhu (2000) suggests that when the method correlates with others we have an convergent validity. On the other hand, discriminant validity is evident when one method does not correlate with other methods because each measures different traits. Mujika et al. (2006) compared performance of players of different standards of competition and playing positions in WIST test. Again, correlated WIST test results in individual match-fitness scores awarded by coaches based on game performance (Mujika, et al., 2006). Likewise, Rechichi et al. (2000) correlated the performance of water polo players in the 10-metre multistage shuttle swim test (MSST) with $\mathrm{VO}_{2 \max }$ as assessed by a swimming ergometer.

Our study was conducted to evaluate sensitivity and validity of the Functional Test for Agility Performance (FTAP) used for water polo players testing. We evaluated sensitivity by comparing seasonal changes in performance on FTAP at two time points (March 2013 and July 2014). Validity was assessed by establishing a relationship between the FTAP and Sprint/Agility Test scores (Rechichi, et al., 2000) and by comparing performance scores of water polo players of different standards. We believe that FTAP has good sensitivity and validity. However, FTAP is an open test whereas the Speed/ Agility Test is a closed test. Thus, these tests may not necessarily show good correlation. In this way, we presumed the occurrence of discriminant validity (Zhu, 2000).

\section{Method}

\section{Research design}

This study was realized in three phases of investigation: one phase to test for sensitivity and two phases to assess validity of FTAP. We tested sensitivity of FTAP by comparing athletic performance at two time points (initial and final). Validity was tested by assessing the relationship between performances on FTAP and Sprint/Agility Test (Rechichi, et al., 2000). Although Sprint/Agility Test is not the gold standard agility test for water polo, its scores can be compared to the scores on FTAP to provide a point of context. Validity was also assessed by comparing performances on FTAP manifested by players of three different standards of competition. Various groups of players were involved in different phases of the investigation and their participation was voluntary. The study was conducted in accordance with the Declaration of Helsinki. The Ethics Committee of the University where the study was conducted approved the protocol and the consent was obtained from participants.

\section{Participants}

\section{Study I - Seasonal changes in performance}

Six elite junior players, who had won silver medals at the 2014 UANA Junior Pan American Championship games, participated in this investigation. The athletes, all field players, were evaluated two times by the same evaluator after a standardized warm-up period. The first FTAP was performed during March 2013 and the second during July 2014. Between FTAP evaluations, the athletes participated in training exercises designed to improve specific areas of their fitness. No training was proposed to exclusively improve performance on FTAP.

\section{Study II - Relationship between FTAP and Sprint/Agility Test}

The same six players who participated in Study I were assessed to test the relationship between FTAP and Sprint/Agility Test.

\section{Study III - Performance of water polo players of different levels}

A total of 65 competitive male water polo players (mean age 18.1 \pm 4.3 years; range, $12-36$ years) participated in this study. All participants were athletes on one of three different water polo teams, and were assigned to one of three groups $\left(\mathrm{G}_{1-3}\right)$ based on their different levels of competition (ages). $G_{1}$ included athletes aged 12 to 14 years (with $3.1 \pm 1.4$ 
years of training experience and $5.0 \pm 1.0$ training sessions per week); $\mathrm{G}_{2}$ included athletes aged 15 to 17 years (with $4.8 \pm 1.8$ years of training experience and $6.0 \pm 1.7$ training sessions per week); $\mathrm{G}_{3}$ included athletes aged over 18 years (with 11.1 \pm 5.1 years of training experience and $6.4 \pm 2.6$ training sessions per week). Weekly frequency of training sessions including tactical functions, drills and competitive level of the athletes are presented in Table 1.

Table 1. Frequency of tactical position and skill level of athletes assessed according their groups

\begin{tabular}{lccccc}
\hline \multirow{2}{*}{ Groups } & \multicolumn{2}{c}{ Tactical position } & \multicolumn{2}{c}{$\begin{array}{c}\text { Competitive } \\
\text { level }\end{array}$} \\
\cline { 2 - 6 } & $\mathrm{P}$ & $\mathrm{C}$ & $\mathrm{G}$ & $\mathrm{N}$ & $\mathrm{I}$ \\
\hline $\mathrm{G} 1(\mathrm{n}=8)$ & 6 & 2 & 0 & 6 & 2 \\
$\mathrm{G} 2(\mathrm{n}=35)$ & 25 & 5 & 5 & 17 & 18 \\
$\mathrm{G} 3(\mathrm{n}=22)$ & 15 & 5 & 2 & 15 & 7 \\
\hline
\end{tabular}

$\mathrm{P}=$ perimeter $\mathrm{C}=$ center; $\mathrm{G}=$ goalkeeper; $\mathrm{N}=$ national;

I=international.

\section{Procedures}

\section{Study I - Seasonal changes in performance}

Data was collected during two assessments. In the first assessment (March 2013), the athletes received joint instruction as a single group regarding the test procedure and performed five FTAP familiarization trials. The evaluator had previously been informed on the FTAP procedures and together with the athletes (tested and passers) was familiarized with the test. Any queries were fully addressed to ensure that all the participants understood the procedures before actual testing. In the second assessment (July 2014), only two-three familiarization trials were performed because athletes had previous knowledge of the test procedure. The same evaluator administered the test on both occasions (initial and final).

\section{Study II - Relationship between FTAP and Sprint/Agility Test}

The data collected during the second assessment of the FTAP sensitivity was used as the reference. The Sprint/Agility Test (Rechichi, et al., 2000) was performed after FTAP.

\section{Study III - Performance of water polo players of different standards}

Athletes on the same team were instructed as a group concerning the test procedures. Due to a limited access to the players involved, three-five FTAP familiarization trials were performed. The same familiarization trails were conducted for the athletes being tested, the players responsible for passing the ball, and the evaluator. FTAP was performed one day after the familiarization session, and the same evaluator administered the test in all the sessions. All queries were fully addressed to ensure that the participants understood the procedures prior to actual testing.

\section{The Functional Test for Agility Performance (FTAP)}

FTAP evaluates agility of a water polo athlete (Tucher, et al., 2014). A player's ability to anticipate future movements, respond appropriately, focus his/ her attention, and make rapid correct decisions is important for good performance (Tucher, et al., 2014). These player's characteristics are essential because the tested athlete does not have prior knowledge of any direction to which the ball or opponent can be displaced; the targets of the tested player's responses are determined by passes taken by the other players. The FTAP's scheme is presented in Figure 1. Numbers B1-B4 depict four balls, and their respective arcs and athletes.

We assessed performance of each athlete within a three-meter-sided square area, as previously proposed (Tucher, et al., 2014). The tested player places him-/herself in one corner within the FTAP square, and has one hand placed on an official water polo ball floating in one arch, which is considered a starting point (Figure 2A). Four other players are positioned outside each of the four FTAP square corners, with one ball in each arch (Figure 1, see B1-B4; Figure 2A). The player next to the tested subject (arch B1) has a fifth ball in his/her hand (see Figure 1; circle with letter B. See Figure 2A). When that player perceives that the tested player has removed his/her hand from the ball and made a rapid movement towards the center of the square, he/she immediately throws the ball to the player located outside the opposite corner (see Figure 1, the player outside arch B1 passed the ball to the player outside arch B2, and Figure 2B. The direction of this pass is obligatory). Upon receiving the ball, this player (arch B2) then passes the ball to either player at his/her sides without indicating the intended direction in order to prevent the tested player's anticipation (the arch B2 player can pass the ball to a player at either arch B3 or B4. See Figure 2C; player in arch $\mathrm{B} 2$ has passed the ball to the player at arch B4). When this movement occurs, the tested player should move as quickly as possible to where the ball has been passed and remove the ball floating in the arch using any part of his/her body (see Figures 2C and 2D). The player who has received the ball (arch B3 or B4) should then pass it once again (the players at arch B3 and B4 are allowed to make a pass only to the players at arch B1 and B2, not to each other. See Figure 2D; the player at arch B4 passed the ball to the player at arch B1). The test is then completed.

It is important to note that the tested player does not know in advance to whom the ball will be passed. In addition, the four other players and the destination of the passes are randomly chosen, and are different for each trial. The test was executed three times for each individual selected from a randomly determined list. The mean value of the 


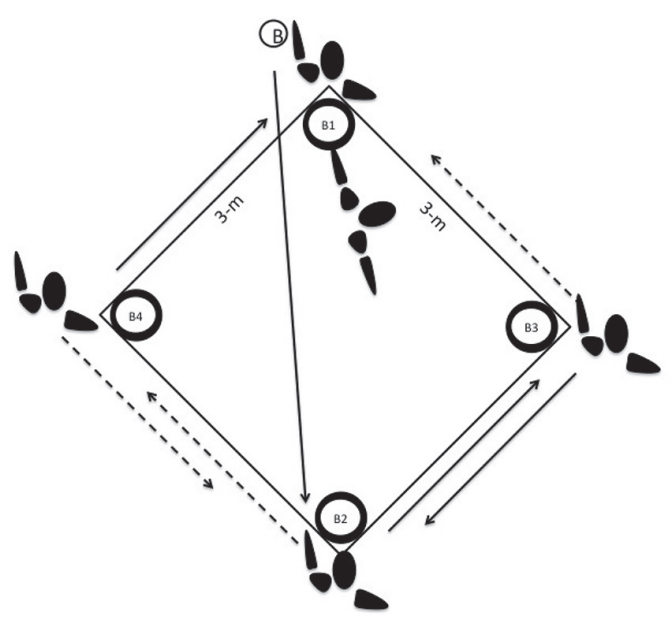

Figure 1. Schematic representation of the Functional Test for Agility Performance (FTAP) proposed to evaluate water polo players during a decision-making task. The tested player (inside the square) removes his/her hand from the ball (B1) and goes towards the center of the square. The ball is passed to the player in the opposite corner (arch B2), who passes it to one of the players at his/her side (B3 or B4). The tested player moves as quickly as possible and removes the floating ball. The ball is passed again (only arch B1 and B2) and the tested player removes that ball for the second time.

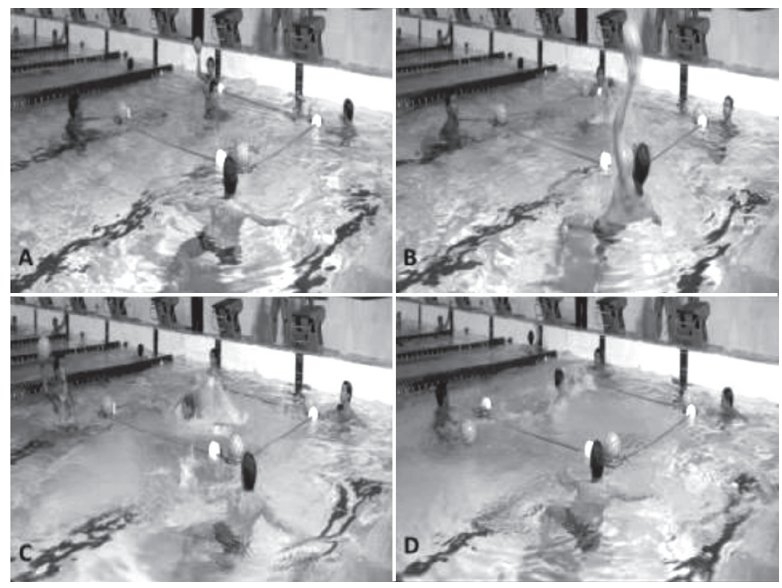

Figure 2. The Functional Test for Agility Performance (FTAP) to evaluate water polo players. Figure $2 A$. Start of the test the player being tested is within the FTAP square and has one hand on the ball. Figure 2B. First pass - the tested player moves to the center of the square. Figure 2C. Second pass the tested player moves to where the ball has been passed and removes the ball floating within the arch. Figure $2 D$. Third pass - the tested player moves to where the ball has been passed again and removes it while floating within the arch. The test is then completed.

three-test results was used as the final result. For this test, a minimum of three minutes of rest was observed between trials. If any unexpected factor occurred that could hinder the athlete's performance on the test (e.g. the tested player moved incorrectly or errors were made in passing) the same player repeated the process after the next athlete on the list had been tested.

The total time taken to perform the test was manually recorded in seconds by a single experienced coach (named evaluator A) using a sport chro- nometer (Professional Stopwatch Vollo Concept model VL233, P. B. Yang Sport, China). The evaluator began to record testing time from the moment the tested player removed his/her hand from the ball in arch B1. Timing was stopped when the tested player removed the second ball from whichever arch (see Figure 2D).

The standardized warm-up consisted of dryland stretching and dynamic joint mobility exercises; then exercises in water included a $200 \mathrm{~m}$ freeswim with alternating front and back strokes and various kick styles; four $100 \mathrm{~m}$ front-crawl swims with no push-off turns every $25 \mathrm{~m}$, starting every 110 seconds, and four $25 \mathrm{~m}$ swims $(12.5 \mathrm{~m}$ sprint, $12.5 \mathrm{~m}$ recovery), starting every 50 seconds. Due to the testing conditions, the evaluations were conducted individually, and the warm-ups were organized to ensure that the test was performed $\leq 5$ minutes after the warm-up. The same warm-up regimen was used in all testing sessions.

\section{The Sprint/Agility Test}

Each player completed three trials of the Sprint/ Agility Test and the best result was recorded (Rechichi, et al., 2000). A minimum of three minutes of rest was secured between trials. Each subject swam a 10 -metre distance as fast as possible. Lane ropes were used to mark the boundaries of the test area. Each player started the test with his/ her head positioned on the lane rope (with body posture selected freely by the player). The athlete then swam to the opposite lane rope and touched it with his/her hand; turned around and swam back to the original lane rope. An additional marker was placed $7 \mathrm{~m}$ from the final lane rope on either side of the pool. A digital HD video camera recorder (Sony HDR-HC9, Japan) was positioned and set to record each trial. The subject started the test after the sound cue stimulated by the evaluator. The videotape was later analyzed using Dartfish Team-Pro 5.0 software. The Sprint/Agility Test provides data regarding acceleration $(0-3 \mathrm{~m})$, the maximum swimming speed (3-7 m) and agility (7-10-7 m) of each athlete. For the current study, we only utilized the data for agility time (7-10-7 m).

\section{Statistics}

The test results are generally presented as the mean value, standard deviation (seconds), minimum (min) and maximum (max) values and 95\% confidence interval for the mean $(95 \% \mathrm{IC})$. The normality of all measures' distribution was assessed using the Shapiro-Wilk's test. The probability of $p \leq .05$ was considered statistically significant.

\section{Study I - Seasonal changes in performance}

Differences in performance on two FTAP tests were assessed using a paired $t$-test. The effect size was calculated by converting the $t$-value in an 
r-value. An effect size $>.50$ was considered greater (Field, 2009).

\section{Study II - Relationship between FTAP and Sprint/Agility Test}

Pearson product-moment correlation coefficients were calculated and used to determine the degree of association between the FTAP time and agility time (s) as determined in the Speed/Agility Test (7-10-7 m).

\section{Study III - Performance of water polo players of different standards}

Analysis of variance (ANOVA) was used to assess differences between the groups $\left(\mathrm{G}_{1-3}\right)$ in FTAP. When appropriate, the Hochberg's GT2 post-hoc procedure was used to identify such differences, because we had unbalanced samples in $\mathrm{G}_{1-3}$ (Field, 2009). Dunnett's test was used to compare $\mathrm{G}_{3}$ and $\mathrm{G}_{2}$ to $\mathrm{G}_{1}$ (as the control group), using a unilateral hypothesis that the mean score of $\mathrm{G}_{1}$ in FTAP should be higher than the mean score of either $\mathrm{G}_{2}$ or $\mathrm{G}_{3}$. The general effect sizes were obtained using omega square $\left(\omega^{2}\right)$ statistics. The specific effect size between the groups was calculated by converting the $t$-value in an r-value. In all cases, an $\omega^{2}$ or $\mathrm{r}>.50$ represented a large effect size (Field, 2009).

\section{Results}

Study I - Seasonal changes in performance

The data for both the initial $(p=.39)$ and final $(\mathrm{p}=.75)$ FTAP evaluations showed normal distributions. The initial FTAP was completed in $4.35 \pm 0.12$ seconds ( $\min =4.13$ seconds; $\max =4.48$ seconds; $95 \% \mathrm{IC}=4.21-4,48$ seconds) and the final FTAP was completed in $4.02 \pm 0.10$ seconds ( $\mathrm{min}=3.87$ seconds; $\max =4.16$ seconds; $95 \% \mathrm{IC}=3.90-4.13$ seconds). On average, athletes completed the final FTAP in fewer seconds than the initial FTAP $(t(5)=6.28, \mathrm{p}=.002$, $\mathrm{r}=.94)$.

\section{Study II - Relationship between FTAP and Sprint/Agility Test}

Both the final FTAP data $(p=.75)$ and agility times in the Speed/Agility Test $(\mathrm{p}=.60)$ showed normal distributions. The final FTAP test was completed in a mean time of $4.02 \pm 0.10$ seconds (as described below) and the Speed/Agility Test was completed in $4.72 \pm 0.22$ seconds ( $\mathrm{min}=4.47$ seconds; $\max =5.10$ seconds; $95 \% \mathrm{IC}=4.48-4.95$ seconds). There was no significant correlation between results on the two tests $\left(\mathrm{r}=.42, \mathrm{R}^{2}=17 \%, \mathrm{p}=.40\right)$.

\section{Study III - Performance of water polo players of different standards}

The data for $\mathrm{G}_{1}(\mathrm{p}=.06), \mathrm{G}_{2}(\mathrm{p}=.58)$, and $\mathrm{G}_{3}$ $(p=.99)$ showed normal distributions. Figure 3 shows that the best FTAP performance was achieved by $\mathrm{G}_{3}$ ( $3.84 \pm 0.27$ seconds; $\min =3.22$ seconds; $\max =4.44$ seconds; $95 \% \mathrm{IC}=3.72-3.96$ seconds), followed by $\mathrm{G}_{2}$ ( $4.11 \pm 0.34$ seconds; $\min =3.42$ seconds; $\max =4.90$ seconds; $95 \% \mathrm{IC}=3.99-4.23$ seconds), and $\mathrm{G}_{1}$ (4.38 \pm 0.32 seconds; $\min =4.02$ seconds; $\max =4.89$ seconds; $95 \% \mathrm{IC}=4.11-4.65$ seconds). We found "standard of competition" had an effect on FTAP results $\left.\left[\mathrm{F}(2,62)=9.45, \mathrm{p}<.001, \omega^{2}=.20\right)\right]$. The Hochberg's GT2 test indicated statistically significant differences between $\mathrm{G}_{1}$ and $\mathrm{G}_{3}(\mathrm{p}<.001 ; \mathrm{r}=0.49)$ and $\mathrm{G}_{2}$ and $\mathrm{G}_{3}(\mathrm{p}=.009 ; \mathrm{r}=0.40)$; however, no differences were found between $G_{1}$ and $G_{2}(p=.10 ; r=0.26)$. Dunnett's test, which used $\mathrm{G}_{1}$ as the control group, showed that $\mathrm{G}_{2}(\mathrm{p}=.03)$ and $\mathrm{G}_{3}(\mathrm{p}<.001)$ needed less time to complete FTAP. A significant linear trend was found, $\mathrm{F}(1,12)=16.39, \mathrm{p}<.001, \omega^{2}=.18$, indicating that time spent in completing FTAP decreased with higher standards of competition (ageing).

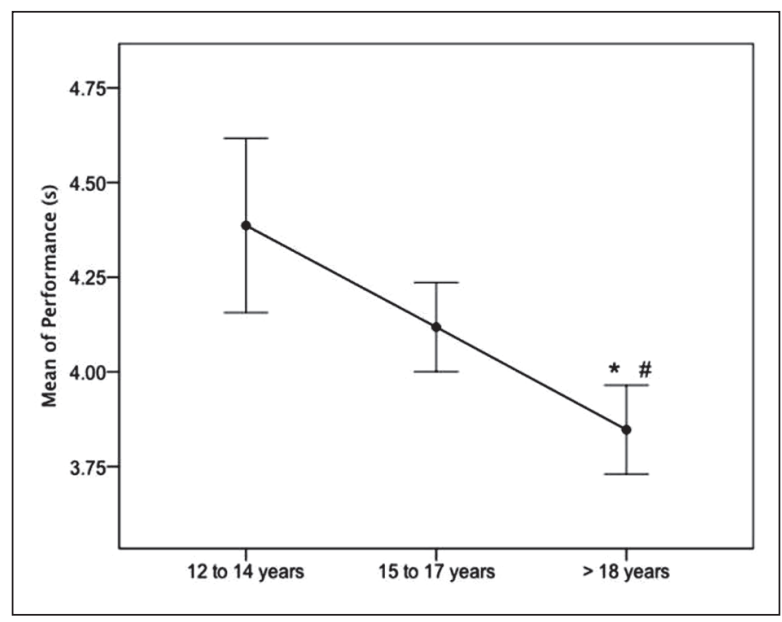

Figure 3. Time needed to perform the Functional Test for Agility Performance (FTAP) decreases along higher standards of competition. Data are presented as the mean \pm standard error. * Denotes a significant difference between G1 and G3 $(p<.001)$ and \# denotes a significant difference between $G 2$ and $G 3(p=.008)$.

\section{Discussion and conclusions}

This study was conducted to evaluate sensitivity and validity of the Functional Test for Agility Performance (FTAP) used to evaluate water polo players. Our results showed that (1) FTAP has a pronounced sensitivity for comparing performances on FTAP made at two time points separated by sixteen months of training. Additionally, final FTAP was completed in less time as compared to initial FTAP. (2) A great validity was shown. We confirmed the evidence of discriminant validity because no correlation was found between results on FTAP and the Sprint/Agility Test - as expected; thus, these two tests measure distinct qualities (Sheppard, et al., 2006; Zhu, 2000). In addition, the differences were found between standard levels of competition. For example, the significant differences were found between $G_{1}-G_{3}$ and $G_{2}-G_{3}$, with the athletes in $\mathrm{G}_{3}$ performing the test in the fewest seconds. While it was expected that $\mathrm{G}_{2}$ would complete FTAP significantly faster than $\mathrm{G}_{1}$, such a 
result was not observed. It is possible that maturational aspects of the athletes and their experience gained with years of water polo training may have influence on this result.

As expected, athletic performance on the final FTAP test was better than on the initial FTAP test. Results of the study conducted by Falk et al. (2004) suggest that selected and non-selected water polo players can improve their capabilities during a twoyear training period. In our study, the time between the initial and final FTAP tests was 16 months, and it is possible that maturation and training experience gained between the tests may have affected athletic performance. Additionally, the effect size for time was higher than that for group in all cases (Falk, et al., 2004), and the effect size for the initial and final testing was also high $(\mathrm{r}=.94)$. We believe that maturational factors associated with athletes' general physical and cognitive capabilities can, in the same way, influence their performance on FTAP. In summary, high levels of training or practice are essential for developing expertise (Baker, Horton, Robertson-Wilson, \& Wall, 2003).

The Speed/Agility Test was proposed as a means to assess athletic agility based on the time spent in transition between 7-10-7 meters (Rechichi, et al., 2000). However, when comparing results on the Speed/Agility Test and FTAP, which also tests agility, no significant association with performance was identified. As suggested by Sheppard et al. (2006) and Zhu (2000), we believe that these two tests measure different qualities. The Speed/Agility Test provides a close assessment when the athlete swims as fast as possible before the movement direction change. The athlete's forward momentum makes it difficult to change movement direction, even though he/she knows when the change will occur. On other hand, during the open test FTAP, the speed of movement direction change may be hampered by the unknown direction of passes. Thus, in FTAP, quick decision-making is evident. However, the number of athletes who participated in this part of the study could be a limiting factor. Meanwhile, Mujika, et al. (2006) found a significant correlation between performance on an intermittent shuttle test (a close test) and a subjective match-fitness performance test scored by two coaches $(\mathrm{r}=.57, \mathrm{n}=12$ - considering field players; $\mathrm{r}=.83, \mathrm{n}=10-$ considering field players other than two center forwards).

The Functional Test for Agility Performance showed trends similar to those observed in previous studies that were conducted to evaluate effectiveness of an open agility test in distinguishing performance of athletes with different standard competition levels (Sheppard, et al., 2006; Uljevic, et al., 2014; Veale, et al., 2010). Although kinematic movement patterns and athletes' perceptual cues were not measured in FTAP, we believe that better performance was positively correlated with a combina- tion of large adjustments in body position, mental attention, and ability to anticipate passes, which was possible due to perceptions of postural cue information (Veale, et al., 2010). For example, we subjectively observed that in FTAP skilled athletes used short rotational movements and both hands to remove the ball floating in an arch. In contrast, novice or less skilled players used inappropriate movements and tended to use only their dominant hand.

Although we expected to find a difference between $G_{1}$ and $G_{2}$ in the performance of different standard levels of water polo players, this did not occur. This result might be explained by two factors. The first is the relative age effect, which seems to influence the acquisition of expertise in sports (Baker, Horton, et al., 2003). It is possible that the age effect is more evident in athletes aged 12-17 years (Burgess \& Naughton, 2010). Uljevic et al. (2014) reported differences in body height between the young national squad and team athletes aged 15-16 years; however, this difference was not found in an older group aged 17-18 years. Thus, in both groups, older players may be bigger, stronger, faster, and better coordinated than their younger counterparts. As a consequence, older players may have experienced greater success and have access to better coaching and training (Baker, Horton, et al., 2003). While the impact of age on test performance tends to decrease starting at 18 years (Burgess \& Naughton, 2010), we did not control for its possible effect in the current study. The other factor effecting athletic performance concerns training. Both the amount of training and its quality are important factors that contribute to athletic performance; however, training factors were not controlled in the study (Baker, Horton, et al., 2003; Ericsson, Krampe, \& Tesch-Römer, 1993).

Falk et al. (2004) compared performances of selected and non-selected young water polo players in a longitudinal study and found no differences in their throwing distances, ability to throw at the net, vertical jump, or results on the $50 \mathrm{~m}$ freestyle and $100 \mathrm{~m}$ breast-stroke swim tests. However, the selected players scored better in the 100, 200, and $400 \mathrm{~m}$ freestyle swims, $100 \mathrm{~m}$ butterfly swim, as well as on tests for ball dribbling and game intelligence. These results suggest that differences were found only in the tests which required specific development of fitness and game skills. In other words, only specific capabilities may differentiate skill of athletes (Baker, Horton, et al., 2003; Veale, et al., 2010). This occurs because the development of specific abilities (e.g. perceptual/cognitive domains), which distinguish experts from nonexperts, are better accounted for by intense training rather than innate abilities (Baker, Horton, et al., 2003). In the same way, Baker, Côté, and Abernethy (2003) compared the reported training programmes 
of experts and non-experts in team sports and found they basically trained using the same activities. However, experts spent overall more time in practice and they devote more time to training specific activities. For example, athletes themselves considered that competition, organized training and video training are the most important activities for developing perception and decision making skills (Baker, Côté, et al., 2003).

Mujika et al. (2006) found differences in distance (m) covered in the Water Polo Intermittent Shuttle Test (aerobic fitness) among athletes of several standards of competition. Characteristics including age (the oldest), gender (male), and level of competition were identified as being important. For example, the first three groups rated "better" were senior elite males, junior elite males, and senior national males; however, there were no significant differences among these groups. There were also no significant differences among five groups rated "the worst." In summary, groups clustered by age or standard of competition were not significantly different. Accordingly, with regard to playing positions, there were no differences among field players and center forwards; however, field players covered more distance than goalkeepers. These results may also show the influence of other variables, such as maturation and training, on player performance in that aerobic test. Similarly, Uljevic et al. (2013) found significant differences among playing positions (center, points, and outer players) for some anthropometric variables. However, in specific motor tests such as jumping capacity, centers were the worst.

In general, it is not possible to fully understand how physical factors, physiological factors, and decision-making influence FTAP results. However, we believe it is important to understand how all these factors work together during an actual game and how FTAP assesses them. Some athletes needed to repeat FTAP more times than others, even though all athletes received the same verbal and practical information. Repeat tests occurred less often among skilled players who understood the test and could explain it. However, mistakes such as not focusing on the ball, passing during their movement, not making quick decisions, and guessing at the direction of passes, all resulted in players making incorrect movements. It was common to hear a coach say: "I have to explain to him every time the importance of knowing where the ball is". These findings reflect the open nature of the FTAP and its similarity to the real game.

We believe that FTAP should be used to test all water polo players at different skill levels. However, certain characteristics of the test make it more applicable for testing defensive actions than offensive actions. This conclusion is based on our perception that we assessed player movements to be the result of a pass, rather than dribbling or throwing at goal. It is possible that an open test would better assess characteristics associated with offensive actions. Falk et al. (2004) suggested that game intelligence should receive great emphasis when selecting young water polo players. The Functional Test for Agility Performance should be used with caution when selecting young athletes and interpreting their performance. It is also important to remember that age greatly influences body anthropometric parameters, body composition, physical and cognitive capabilities, and consequently, training opportunities (Baker, Horton, et al., 2003). These characteristics may all somehow influence an athlete's momentary performance on FTAP.

The main finding of this investigation was that the Functional Test for Agility Performance showed high both sensitivity and validity. Additionally, the significant difference in results was found when FTAP was administered pre and post training period. Our results suggest that certain aspects of maturation and training experience have some influence on the test results. Performance on FTAP was not associated with performance on the Speed/ Agility Test. This could be expected because FTAP is an open test, in which decision-making is important, while the Speed/Agility Test involves only close action skills - evidencing the discriminant validity. It was also possible to detect performance differences among players based on their standard of competition (player age). However, it must be remembered that characteristics such as maturational stage, anthropometric body type, expertise, quality of training, tactical position, and skill level may influence athletes' performance on FTAP.

\section{References}

Alcaraz, P.E., Abraldes, J.A., Ferragut, C., Rodríguez, N., Argudo, F.M., \& Vila, H. (2011). Throwing velocities, anthropometric characteristics, and efficacy indices of Women's European Water Polo Subchampions. Journal of Strength and Conditioning Research, 25(11), 3051-3058.

Aleksandrović, M., Naumovski, A., Radovanović, D., Georgiev, G., \& Popovski, D. (2007). The influence of basic motor abilities and anthropometric measures on the specific motor skills of talented water polo players. Journal of Physical Education and Sport, 5(1), 65-74.

Baker, J., Côté, J., \& Abernethy, B. (2003). Learning from the experts: Practice activities of expert decision makers in sport. Research Quarterly for Exercise and Sport, 74(3), 342-347. 
Baker, J., Horton, S., Robertson-Wilson, J., \& Wall, M. (2003). Nurturing sport expertise: Factors influencing the development of elite athlete. Journal of Sports Science and Medicine, 2(1), 1-9.

Bampouras, T.M., \& Marrin, K. (2009). Comparison of two anaerobic water polo-specific tests with the Wingate Test. Journal of Strength and Conditioning Research, 23(1), 336-340.

Bangsbo, J., Iaia, F.M., \& Krustrup, P. (2008). The Yo-Yo intermittent recovery test: A useful tool for evaluation of physical performance in intermittent sports. Sports Medicine, 38(1), 37-51.

Burgess, D.J., \& Naughton, G.A. (2010). Talent development in adolescent team aports: A review. International Journal of Sports Physiology and Performance, 5(1), 103-116.

Currell, K., \& Jeukendrup, A.E. (2008). Validity, reliability and sensitivity of measures of sporting performance. Sports Medicine, 38(4), 297-316.

Ericsson, K.A., Krampe, R.T., \& Tesch-Römer, C. (1993). The role of deliberate practice in the acquisition of expert performance. Psychological Review, 100(3), 363-406.

Falk, B., Lidor, R., Lander, Y., \& Lang, B. (2004). Talent identification and early development of elite water-polo players: A 2-year follow-up study. Journal of Sports Sciences, 22(4), 347-355.

Ferragut, C., Vila, H., Abraldes, J., Argudo, F., Rodriguez, N., \& Alcaraz, P. (2011). Relationship among maximal grip, throwing velocity and anthropometric parameters in elite water polo players. Journal of Sports Medicine and Physical Fitness, 51(1), 26.

Field, A. (2009). Discovering statistics using SPSS (2 $2^{\text {nd }}$ ed.). Porto Alegre: Artmed.

Impellizzeri, F.M., \& Marcora, S.M. (2009). Test validation in sport physiology: Lessons learned from clinimetrics. International Journal of Sports Physiology and Performance, 4(2), 269-277.

Kos, H., Rynkiewicz, M., Zurek, P., Zabski, S., \& Rynkiewicz, T. (2010). Maximal strength and strength accuracy in water polo players from the Polish Junior National team. Studies in Physical Culture and Tourism, 17(4), $307-313$.

Mujika, I., McFadden, G., Hubbard, M., Royal, K., \& Hahn, A. (2006). The water-polo intermittent shuttle test: A matchfitness test for water-polo players. International Journal of Sports Physiology and Performance, 1(1), 27-39.

Platanou, T. (2006). Simple "in-water" vertical jump testing in water polo. Kinesiology, 38(1), 57-62.

Rechichi, C., Dawson, B., \& Lawrence, S.R. (2000). A multistage shuttle swim test to assess aerobic fitness in competitive water polo players. Journal of Science and Medicine in Sport, 3(1), 55-64.

Sheppard, J.M., \& Young, W. (2006). Agility literature review: Classifications, training and testing. Journal of Sports Sciences, 24(9), 919-932.

Sheppard, J.M., Young, W.B., Doyle, T.L.A., Sheppard, T.A., \& Newton, R.U. (2006). An evaluation of a new test of reactive agility and its relationship to sprint speed and change of direction speed. Journal of Science and Medicine in Sport, 9(4), 342-349.

Tucher, G., Castro, F.A.S., Garrido, N., \& Silva, A.J. (2014). The reliability of a functional agility test for water polo. Journal of Human Kinetics 41, 129-137.

Uljevic, O., Esco, M.R., \& Sekulic, D. (2014). Reliability, validity, and applicability of isolated and combined sportspecific tests of conditioning capacities in top-level junior water polo athletes. Journal of Strength and Conditioning Research, 28(6), 1595-1605.

Uljevic, O., Spasic, M., \& Sekulic, D. (2013). Sport-specific motor fitness tests in water polo: Reliability, validity and playing position differences. Journal of Sports Science and Medicine, 12(4), 646-654.

Veale, J.P., Pearce, A.J., \& Carlson, J.S. (2010). Reliability and validity of a reactive agility test for Australian football. International Journal of Sports Physiology and Performance, 5(2), 239-248.

Young, W., \& Willey, B. (2010). Analysis of a reactive agility field test. Journal of Science and Medicine in Sport, 13(3), 376-378.

Zhu, W. (2000). Which should it be called: convergent validity or discriminant validity? Research Quarterly for Exercise and Sport, 71(2), 190-194.

Submitted: October 31, 2014

Accepted: January 20, 2016
Correspondence to:

Guilherme Tucher

Center of PE and Health,

Federal Institute of Education, Science and

Technology of the Southeast of Minas Gerais

Av. Dr. José Sebastião da Paixão s/n ${ }^{\circ}$

Bairro Lindo Vale - Rio Pomba / MG, Brazil - CEP:

36180-000

Phone: (5532) 3571-5700

E-mail: guitucher@yahoo.com.br

The authors acknowledge the support of all the athletes and their coaches who participated in the study. 